American Journal of Biochemistry and Biotechnology 4 (4): 402-407, 2008

ISSN 1553-3468

(C) 2008 Science Publications

\title{
Antibacterial and Antioxidant Activities of Typhonium Flagelliforme (Lodd.) Blume Tuber
}

\author{
${ }^{1}$ Syam Mohan, ${ }^{1,2}$ Ahmad Bustamam Abdul, ${ }^{1}$ Siddig Ibrahim Abdel Wahab, ${ }^{1,3}$ Adel Sharaf Al-Zubairi, \\ ${ }^{1}$ Manal Mohamed Elhassan and ${ }^{1}$ Mohammad Yousif \\ ${ }^{1}$ Upm-makna Cancer Research Laboratory, Institute of Bioscience, \\ 43400 UPM Serdang, University Putra Malaysia, Malaysia \\ ${ }^{2}$ Department of Biomedical Sciences, Faculty of Medicine and Health Sciences, \\ 43400 UPM Serdang, University Putra Malaysia, Malaysia \\ ${ }^{3}$ Department of Clinical Biochemistry, University of Sana'a, Sana'a, Yemen
}

\begin{abstract}
Problem Statement: Multiple drug resistance in human pathogenic micro organisms has developed due to indiscriminate use of modern antimicrobial drugs generally used in the management of infectious diseases. This increases the importance of exploiting the natural sources instead modern drugs. Approach: The antibacterial and antioxidant activity of different extracts from of Typhonium flagelliforme (L.) Blume tuber (family: Araceae) commonly called 'Rodent Tuber' was assessed towards selected bacteria as well as in different antioxidant models. The antibacterial screening was carried out by disc diffusion method. Two complementary test systems, namely DPPH free radical scavenging and total phenolic compounds, were used for the antioxidant analysis. Results: Except hexane extract none of the other extracts shown anti bacterial activity against the selected strains. The hexane extract from Typhonium flagelliforme tuber had interesting activity against both the gram negative bacteria, Pseudomonas aeruginosa (11 $\pm 1.0 \mathrm{~mm}$ diameter) and Salmonella choleraesuis $(12 \pm 1.1 \mathrm{~mm}$ diameter). The positive control, Streptomycin had shown zone of inhibition of $20 \pm 1.5$ $\mathrm{mm}, 20 \pm 1.3 \mathrm{~mm}, 23 \pm 1.5 \mathrm{~mm}$ and $23 \pm 1.0 \mathrm{~mm}$ in Methicillin Resistant Staphylococcus aureus, Pseudomonas aeruginosa, Salmonella choleraesuis and Bacillus subtilis respectively. All the extracts were subjected to screening for their possible antioxidant activity. The DPPH assay showed that the inhibitory activity of ethyl acetate $(77.6 \pm 0.9 \%)$ and dichloromethane $(70.5 \pm 1.7 \%)$ extracts were having comparatively admirable inhibition capacity when compared to the positive control BHT $(95.3 \pm 1.3 \%)$. Total phenolic content of all extracts was also evaluated, and dichloromethane extracts (5.21 $\pm 0.82 \mathrm{GAE} \mathrm{mg} / \mathrm{g}$ extract) was superior to all other extracts, followed by hexane and ethyl acetate. Conclusion: Considering all the results collectively $T$. flagelliforme appears to be a promising plant demonstrating antibacterial and antioxidant activity that requires further investigation.
\end{abstract}

Key words: Typhonium flagelliforme, rodent tuber, antibacterial activity, antioxidant activity, fatty acids

\section{INTRODUCTION}

Plants are more important in human's life and fulfil his every day's needs. They are used as cosmetic, food, flavours, ornamental and medicine. The higher plants are used to treat a number of infectious diseases around the world. They provide an innumerable of natural products, which are used in extensive applications in combating the diseases.

Medicine is used for treating diverse ailments. Malaysia possesses an immense number of medicinal plants $^{[1]}$. Even if medicinal plants are used and distributed throughout the world, they are more plentifully present in tropical countries like Malaysia. These medicinal plants are one of the best resources for the invention and development of novel bioactive substances ${ }^{[2]}$. Several studies indicated that medicinal plants contain substances like peptide, unsaturated long chain fatty acids, aldehydes, alkaloids, essential oils, phenols and water or ethanol soluble compounds. These compounds are potentially significant in therapeutic applications against human and animal pathogens, including bacteria, fungi and viruses ${ }^{[3,4]}$.

Oxidation is essential in many living organisms for the production of energy to fuel biological processes. However, the uncontrolled production of oxygen

Corresponding Author: Dr.Ahmad Bustamam Abdul, UPM-MAKNA Cancer Research Laboratory,Institute of Bioscience, University Putra Malaysia, 
derived free radicals is involved in the onset of many diseases such as atherosclerosis, rheumatoid arthritis, and cancer as well as in degenerative processes associated with aging ${ }^{[5]}$. Almost all organisms are well protected against free radical damage by enzymes such as superoxide dismutase and catalase, or compounds such as ascorbic acid, tocopherols and glutathione ${ }^{[6]}$. When the mechanism of antioxidant protection becomes unbalanced by factors such as aging, deterioration of physiological functions may occur resulting in diseases and accelerated aging. However, the antioxidants present in human diet are of great interest as possible protective agents to help the human bodies reduce oxidative damage.

Researchers have reported the antimicrobial activity of several herbal plants ${ }^{[7,8]}$. In recent years, multiple drug resistance in human pathogenic micro organisms has developed due to indiscriminate use of commercial antimicrobial drugs commonly used in the treatment of infectious diseases. This situation has forced scientists to search for new antimicrobial substances from various sources as novel antimicrobial chemotherapeutic agents ${ }^{[9]}$. The cost of production of synthetic drugs is also high and they produce adverse effect compared to plants derived drugs. Hence much attention has been paid recently, to the biologically active compounds derived from plants used in herbal medicine ${ }^{[10]}$.

Typhonium flagelliforme (Lodd.) Blume (Araceae) is a herbal plant which grows up to $30 \mathrm{~cm}$ in height. It has an oblong whitish tuber, triangular leaves and a spathe. The occasionally beautiful and often bizarre combination of spathe and spadix called the inflorescence, sometimes referred to as a flower is a distinguishing feature of all aroids, which has been used for trapping their pollinators because of their particular morphology and organization of their inflorescences ${ }^{[11]}$. This plant grows wild in wasteland and is native to the South East Asian countries and the southern part of India and Sri Lanka ${ }^{[12]}$. As a general practice, the juice of the fresh whole Typhonium flagelliforme plant is prepared in honey to be consumed as a drink. There are also other practices where the leaves are wrapped in Longan flesh and taken raw ${ }^{[13]}$.

Hexane extract of $T$. flagelliforme, displayed poor cytotoxic activity against in vitro $\mathrm{P} 388$ murine leukemia cells ${ }^{[12]}$. A low cytotoxic activity has been exhibited by the polar fraction of this plant, with crude water extract being able to reduce lymphoidal cells growth in vitro ${ }^{[14]}$. T. flagelliforme, were also used to provide relief in cough and asthma, which was experimentally verified that water, alcohol and ester extract could significantly decrease cough times, prolong asthma incubation period, decrease twisting times, inhibit ear swelling and decrease autonomic action times $^{[15]}$.

Several chemical constituents had been identified from $T$. flagelliforme. The hexane extract was reported to contain saturated hydrocarbons and aliphatic acids ${ }^{[16]}$, while the ethyl acetate extract was found to contain aromatic fatty acids ${ }^{[16]}$. No biological activities were indicated for these compounds. In addition, phenylpropanoid glycosides, sterols, and a cerebroside which has anti hepatotoxic activity were reported from the root of this plant ${ }^{[17]}$. Pharmacological studies conducted on rats also indicated that the juice extract was able to prevent hepatocarcinogenesis ${ }^{[13]}$.

The aim of this study was to evaluate the in vitro antibacterial activity of the $T$. flagelliforme tuber against Gram-positive and Gram-negative bacteria and its antioxidant activity.

\section{MATERIALS AND METHODS}

Collection of plant materials: T. flagelliforme (Lodd.) Blume tubers were collected in July 2007 from the state of Selangor, Malaysia. Authentication was done at the Department of Botany, Faculty of Science, University Putra Malaysia where voucher specimen TF-T100156 was deposited.

Extraction procedure: Fresh Plant $(10 \mathrm{~kg})$ were harvested and washed thoroughly with running tap water and then distilled water, followed by separation in to aerial parts as well as tubers before drying. The tubers were air dried and then oven dried at reduced temperature. The fully dried plant were powdered and weighed before cold maceration. The powdered tuber (398 gm) was extracted with different solvents in the order of increasing polarity. The solvents used were hexane, dichloromethane, ethyl acetate and methanol. The extraction was done for 7 days with occasional shaking and the process was repeated for three times. The combined extracts were filtered through Whatman ${ }^{\circledR}$ No. 41 filter paper (pore size 20-25 $\mu \mathrm{m}$ ) and dried under vacuum using a rotary evaporator and then weighed to calculate the yield of the extracts and stored at $4^{\circ} \mathrm{C}$ until required.

Antibacterial activity:

Bacterial strains: The antibacterial activity of plant extracts was evaluated using two Gram-positive bacteria, Methicillin Resistant Staphylococcus Aureus (MRSA) and Bacillus subtilis B29, and other two Gram-negative bacteria, Pseudomonas aeruginosa 60690 and Salmonella choleraesuis. All the bacterial 
strains were obtained from Laboratory of Molecular Biomedicine, Institute of Bioscience, University Putra Malaysia, Serdang, Malaysia.

Antibacterial Assay: The screening of the extracts on antibacterial effect was carried out by determining the zone of inhibition using paper disc (6 $\mathrm{mm}$ in diameter, Whatman No. 1) diffusion method $^{[18,19]}$. The obtained micro organism strains were inoculated in a Petri dish containing nutrient broth at $37^{\circ} \mathrm{C}$ for $24 \mathrm{~h}$ and were referred as seeded broth. The density of the bacterial suspension was standardized by standard method and the concentrations of the cultures were adjusted turbidometrically at wavelength of $600 \mathrm{~nm}$ to $500,000-1000,000$ colony forming unit per $\mathrm{mL}$ (CFU $\mathrm{mL}^{-1}$ ). The extracts were dissolved in dimethyl sulphoxide which was previously tested for antibacterial activity against all test bacteria and found to have no antibacterial activity. The extracts were diluted to concentration of $100 \mathrm{mg} \mathrm{mL}^{-1}$ and finally sterilized by filtration using $0.45 \mu \mathrm{m}$ millipore filters. The sterile discs were impregnated with extract solution $\left(0.05 \mathrm{~mL}\right.$ from $100 \mathrm{mg} \mathrm{mL}^{-1}$ extract) to achieve desired concentration and placed in inoculated agar. Streptomycin $(10 \mu \mathrm{g} /$ disc $)$ was used as standard. The controls were prepared using the same solvents without extracts. The inoculated plates contain the test and standard discs were incubated at $37^{\circ} \mathrm{C}$ for $24 \mathrm{~h}$.

\section{Antioxidant Assay:}

Amount of total phenolic compounds: The amount of Total Phenolics (TPC) in the extracts was determined using the Folin-Ciocalteu reagent method ${ }^{[20]}$. Stock solutions of $T$. flagelliforme extracts were prepared in a concentration of $20 \mathrm{mg} / \mathrm{ml}$, a $50 \mu \mathrm{L}$ from this solution was transferred to a test tube $(n=3)$. To this tube, 0.4 $\mathrm{mL}$ of Folin-Ciocalteu reagent $(1: 10)$ was added and the tube was shaken thoroughly. After $1 \mathrm{~min}, 0.8 \mathrm{~mL}$ of sodium bicarbonate solution $\left(\mathrm{NaHCO}_{3} 7.5 \%\right)$ was added and the mixture was allowed to stand for $30 \mathrm{~min}$ with intermittent shaking. Absorbance was measured at $765 \mathrm{~nm}$ using a Shimadzu UV-Vis spectrophotometer. The total phenolic content was expressed as Gallic Acid Equivalents (GAE) in $\mathrm{mg}$ per $\mathrm{g}$ extract from the calibration curve of gallic acid standard solution. For the gallic acid, the curve was established by plotting concentration (mg mL $\mathrm{mL}^{-1}$ ) versus absorbance $(\mathrm{nm})\left(\mathrm{y}=5.145 \mathrm{x}+0.014 ; \mathrm{R}^{2}=0.9975\right)$. Here $\mathrm{y}=$ Absorbance and $\mathrm{x}=$ Concentration.

DPPH radical scavenging assay: Radical scavenging activity of plant extracts against stable DPPH $(2,2-$ diphenyl-2-picrylhydrazyl hydrate, Sigma-Aldrich Chemie, Steinheim, Germany) was determined spectrophotometrically. When DPPH reacts with an antioxidant compound, which can donate hydrogen, it is reduced. The changes in color (from deep-violet to light-yellow) were measured at $517 \mathrm{~nm}$ wavelength.

Radical scavenging activity of extracts was measured by slightly modified method of Changwei et $a l .^{[21]}$ as described below. Extract stock solutions were prepared in $100 \mathrm{mg} / \mathrm{ml}$ in ethanol. Methanol extract was not fully soluble in ethanol (even after treating solutions for $5 \mathrm{~min}$ in an ultrasonic bath), therefore it was dissolved in dimethylsulphoxide. The working solution was prepared using methanol in a concentration of $500 \mu \mathrm{g} \mathrm{mL}^{-1}$. The solution of DPPH in methanol $2.5 \mathrm{mg} \mathrm{mL}$ was prepared daily, before UV measurements. $5 \mu \mathrm{L}$ of this solution were mixed with $100 \mu \mathrm{l}$ extract solution 96 well plate. The samples were kept in the dark for $30 \mathrm{~min}$ at ambient temperature and then the decrease in absorption was measured by using microtitre plate reader (Labsystems iEMS Reader MF). Absorption of blank sample containing the same amount of methanol and DPPH solution was prepared and measured daily. The experiment was carried out in triplicate. Radical scavenging activity was calculated by the following formula:

$$
\% \text { Inhibition }=\left[\left(\mathrm{A}_{\mathrm{B}}-\mathrm{A}_{\mathrm{A}}\right) / \mathrm{A}_{\mathrm{B}}\right] \times 100
$$

where:

$A_{B}=$ Absorption of blank sample $(t=0$ min $)$

$A_{A}=$ Absorption of tested extract solution $(t=30 \mathrm{~min})$.

Commercial standard antioxidant Butylated Hydroxyl Toluene (BHT) was also tested against DPPH and used as a reference.

\section{RESULTS}

In this study, some of biological activities of $T$. flagelliforme tuber have been investigated, whereby; hexane, dichloromethane, ethyl acetate and methanol extracts of $T$. flagelliforme tuber were assayed for their antibacterial and anti-oxidant properties using disc diffusion method, DPPH assay and total phenolic compounds, respectively.

The antibacterial activity results are shown in Table 1. Our findings showed that except hexane extract none of the other extracts shown any activity against the selected strains. The hexane extract from $T$. flagelliforme tuber had interesting activity against gram negative bacteria. In which the activity was against Pseudomonas aeruginosa $11 \pm 1.0 \mathrm{~mm}$ diameter and Salmonella choleraesuis $12 \pm 1.1 \mathrm{~mm}$ diameter. The positive control, Streptomycin had shown zone of inhibition of $20 \pm 1.5 \mathrm{~mm}, 20 \pm 1.3 \mathrm{~mm}, 23 \pm 1.5 \mathrm{~mm}$ and $23 \pm 1.0 \mathrm{~mm}$ in Methicillin Resistant Staphylococcus aureus, Pseudomonas aeruginosa, Salmonella choleraesuis and Bacillus subtilis respectively. 
Table 1: Paper disk diffusion of T. flagelliforme tuber growth ${ }^{\mathrm{a}}$

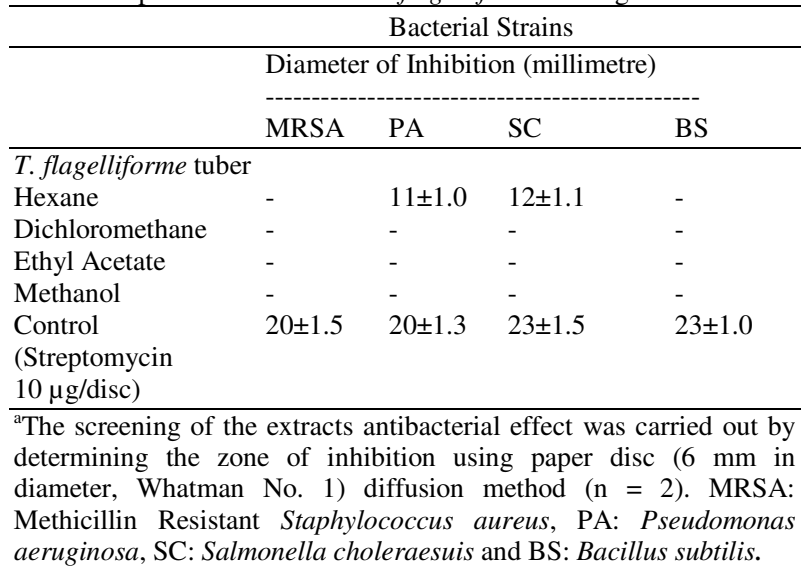

Table 2: Total phenolic content in T. flagelliforme tuber extracts

\begin{tabular}{lc}
\hline T. flagelliforme Tuber & Total phenolic content as gallic acid \\
\hline Extracts & equivalents $\left(\mathrm{GAE} \mathrm{mg} \mathrm{g} \mathrm{g}^{-1}\right.$ extract) \\
Hexane & $3.27 \pm 0.85^{\mathrm{b}}$ \\
Dichloromethane & $5.21 \pm 0.82^{\mathrm{b}}$ \\
Ethyl Acetate & $2.49 \pm 0.33^{\mathrm{a}}$ \\
Methanol & $2.20 \pm 0.25^{\mathrm{c}}$
\end{tabular}

Each value in the table is represented as mean $\pm \operatorname{SE}(n=3)$; different letters in the same column indicate significant difference $(\mathrm{P}<0.05)$

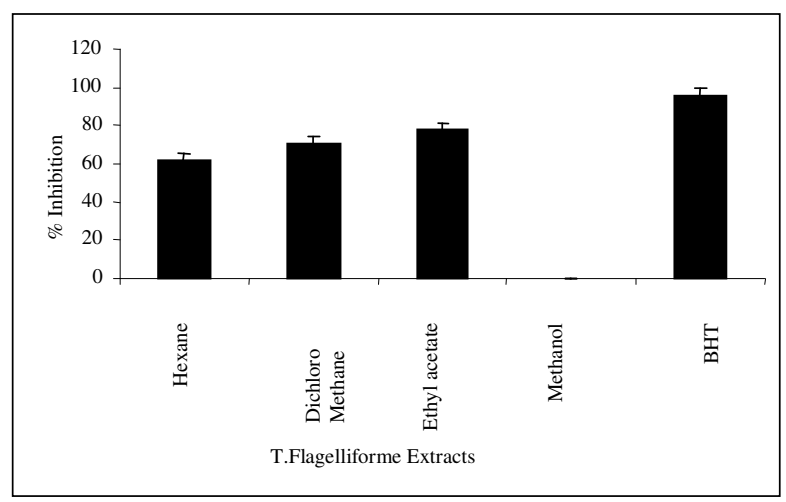

Fig. 1: Free radical scavenging capacities of the $T$. flagiliforme tuber extracts measured in DPPH assay

All the extracts were subjected to screening for their possible antioxidant activity. Two complementary test systems, namely DPPH free radical scavenging and total phenolic compounds were used for the analysis. $\mathrm{DPPH}$, a stable free radical with a characteristic absorption at $517 \mathrm{~nm}$, was used to study the radical scavenging effects of extracts. As antioxidants donate protons to these radicals, the absorption decreases. The decrease in absorption is taken as a measure of the extent of radical scavenging. Free radical scavenging capacities of the extracts, measured by DPPH assay, are shown in Fig. 1. The results showed that the inhibitory activity of ethyl acetate $77.6 \pm 0.9 \%$ and dichloromethane $70.5 \pm 1.7 \%$ extracts were comparatively admirable inhibition capacity when compared to the positive control BHT 95.3 $\pm 1.3 \%$. The total phenolic content of dichloromethane extracts $5.21 \pm 0.82 \mathrm{GAE} \mathrm{mg} \mathrm{g}^{-1}$ extract was superior to all other extracts, followed by hexane and ethyl acetate (Table 2).

\section{DISCUSSION}

Our results showed considerable antibacterial activity of the hexane extract, especially against gram negative strains. This is probably due to saturated fatty acids present in the extract, which was well documented $^{[16]}$. Saturated fatty acids have been studied extensively on their antibacterial activity ${ }^{[22,23]}$. Due to the continuous emergence of antibiotic-resistant strains there is continual demand for new antibiotics. In many developing countries about $80 \%$ of available drugs come from medicinal plants and in industrialized countries plants make up the raw material for processes, which synthesize pure chemical derivatives ${ }^{[24]}$.

Both the complementary test reveals that dichloromethane and ethyl acetate extracts are showing good anti oxidant activity. The growing interest in the substitution of synthetic food antioxidants with natural ones has fostered research on plant sources and screening of raw materials to identify new antioxidants. In this view some biological properties such as anticarcinogenicity, antimutagenicity, antiallergenicity and antiaging activity have been reported for natural and synthetic antioxidants ${ }^{[25]}$. Polyphenols are the major plant compounds with antioxidant activity, although they are not the only ones. The antioxidant activity of phenolic compounds is reported to be mainly due to their redox properties ${ }^{[26,27]}$, which can play an important role in adsorbing and neutralizing free radicals, quenching singlet and triplet oxygen, or decomposing peroxides.

\section{CONCLUSION}

The experiments described above demonstrated that $T$. flagelliforme tuber extracts possess compounds with significant antibacterial and antioxidant effect which could be purified from the respective extracts. The further isolation of such bioactive components could perhaps clarify the pharmacological properties of T. flagelliforme tuber and be further exploited for pharmaceutical use. 


\section{ACKNOWLEDGMENT}

We greatly acknowledge the financial support provided by University Putra Malaysia and National Cancer society (MAKNA), Malaysia. Gratitude also extends to all staffs of UPM-MAKNA Laboratory for Cancer Research, Institute of Bioscience, University Putra Malaysia for their assistance in our work.

\section{REFERENCES}

1. Lin, K.W., 2005. Ethnobotanical study of medicinal plants used by the Jah Hut peoples in Malaysia. Indian J Med Sci., 59:156-61. http://www.indianjmedsci.org/temp/IndianJMedSci 594156-8479652_233316.pdf.

2. Tomoko, N., A. Takashi, T. Hiromu, I. Yuka, M. Hiroko, I. Munekazu, T. Totshiyuki, I. Tetsuro, A. Fugio, I. Iriya, N. Tsutomu and W. Kazuttito, 2002. Antibacterial activity of extracts prepared from tropical and sub tropical plants on methicillin resistant Staphylococcus aureus. J. Health Sci., 48: 273-289. http://jhs.pharm.or.jp/data/48(3)/48_273.pdf.

3. Iwu, M.M., A.R. Duncan and C.O. Okunji, 1999. New antimicrobials of plant origin. In: Prospective on New Crops and New Uses, Janick J. (Ed.). ASHS Press, Alexandria, VA., pp: 457-462. http://www.hort.purdue.edu/newcrop/proceedings1 999/pdf/v4-457.pdf.

4. Khan, M., M. Kibara and B. Oinoloso, 2003. Antibacterial activity of the alkaloidal constituents of the root bark of Eupomatia lourina. Pharmaceut. Biol., 41: 277-280. DOI: 0.1076/phbi.41.4.277.15671.

5. Halliwell, B. and J.M.C. Gutteridge, 1984. Lipid peroxidation, oxygen radicals, cell damage, and antioxidant therapy. The Lancet., 323: 1396-1397. http://www.ncbi.nlm.nih.gov/pubmed/6145845.

6. Mau, J.L., H.C. Lin and S.F. Song, 2002. Antioxidant properties of several specialty mushrooms. Food Res. Int., 35: 519-526. DOI: 10.1016/S0963-9969(01)00150-8.

7. Shai, L.J., L.J. McGawa, M.A. Aderogbaa, L.K. Mdeea and J.N. Eloff, 2008. Four pentacyclic triterpenoids with antifungal and antibacterial activity from Curtisia dentata (Burm.f) C.A. Sm. Leaves. J. Ethnopharmacol., 119: 238-244. DOI: 10.1016/j.jep.2008.06.036.

8. Firas A., Al-Bayati, 2008. Synergistic antibacterial activity between Thymus vulgaris and Pimpinella anisum essential oils and methanol extracts. J. Ehnopharmacol., $\quad 116$ : 403-406. DOI: 10.1016/j.jep.2007.12.003
9. Karaman., F. Sahin, M. Güllüce, H. Ögütçü, M. Sengül and A. Adıgüzel, 2003. Antimicrobial activity of aqueous and methanol extracts of Juniperus oxycedrus L. J. Ethnopharmacol., 85: 213-235. DOI: 10.1016/S0378-8741(03)00006-0

10. Essawi, T., 2000. Screening of some Palestinian medicinal plants for antimicrobial activity. J. Ethnopharmocol., $\quad 70: \quad 343-349 . \quad$ DOI: 10.1016/S0378-8741(99)00187-7.

11. Jerome, A., Q. Angelique and G. Marc, 2001. Pollination ecology of Arum italicum (Araceae). Botanical J. Linnean Soc., 141: 205-214. DOI: 10.1046/j.1095-8339.2003.00139.x.

12. Chee, Y.C., L.C. Kit., T. Koichi and I. Hideji, 2001. Cytotoxic activity of Typhonium flagelliforme (Araceace). Phytotherapy Res., 15: 260-262.

http://www3.interscience.wiley.com/journal/80503 177/abstract?CRETRY=1\&SRETRY $=0$.

13. Choon, S. L., H.M.H. Rosemal, N.K. Nair, M.I.A. Majid, S.M. Mansor and V. Navaratnam, 2008. Typhonium flagelliforme inhibits cancer cell growth in vitro and induces apoptosis: An evaluation by the bioactivity guided approach. J. Ethnopharmacol., 118 : 14-20. DOI: 10.1016/j.jep.2008.02.034.

14. Chee, Y.C., L.C. Kit., W.S. Teng., H. Yukio and T. Koichi, 2001. The cytotoxicity and chemical constituents of the hexane fraction of Typhonium flagelliforme (Araceae). J. Ethnopharmacol., 77: 129-131. DOI: 10.1016/S0378-8741(01)002744.

15. Zhong, Z., G. Zhou., X. Chen and P. Huang., 2001. Pharmacological study on the extracts from Typhonium flagelliforme. J. Chinese Med. Mater., 24: $735-738$ http://grande.nal.usda.gov/ibids/index.php?mode2= detail\&origin=ibids_references\&therow $=734970$.

16. Chen, S.X., C.J. Gohand and O.L. Kon, 1997. Fatty acids from Typhonium flagelliforme. Planta Medica., 63: 580-583. http://grande.nal.usda.gov/ibids/index.php?mode2= detail\&origin=ibids_references\&therow $=536372$.

17. Huang, P., G. Karagianis and P.G. Waterman, 2004. Chemical constituents from Typhonium flagelliforme. Zhongyaocai., 27: 173-175. http://www.ncbi.nlm.nih.gov/pubmed/15272778.

18. Sahoo, S., D.M. Kar, S. Mohapatra, S.P. Rout and S.K. Dash, 2006. Antibacterial activity of Hybanthus enneaspermus against selected UTI pathogens. Ind. J. Pharma. Sci., 68: 653-655. http://www.ijpsonline.com/temp/IndianJPharmSci6 85653-2204888_060728.pdf . 
19. Prusti, A., S.R. Mishra, S. Sahoo and S.K. Mishra, 2008. Antibacterial Activity of Some Indian Medicinal Plants. Ethnobotanical Leaflets., 12: 227-230. http://www.siu.edu/ ebl/leaflets/abp.htm.

20. Djeridane, A., M. Yousfi, B. Nadjemi, D. Boutassouna, P. Stocher and N. Vidal, 2006. Antioxidant activity of some Algerian medicinal plants extracts containing phenolic compounds. Food Chem., 97: 654-660. DOI: 10.1016/j.foodchem.2005.04.028.

21. Changwei, A., L. Anping, A. E. Abdelnaser., D. X. Tran and T. Shinkichi, 2008. Evaluation of antioxidant and antibacterial activities of Ficus microcarpa L. fil. Extract. Food Control, 19: 940948. DOI: 10.1016/j.foodcont.2007.09.007

22. Michael, S., K.T. Mathew b and G. Simon, 2006. Antimicrobial constituents of Scrophularia deserti. Phytochemistry., 67: 1530-1533. DOI: 10.1016/j.phytochem.2006.05.011.

23. Galbraith H., T. B. Miller, A. M. Paton and J.K. Thompson, 2008. Antibacterial activity of long chain fatty acids and the reversal with calcium, magnesium, ergocalciferol and cholesterol. J. Appl. Microbiol., 34, 803.813. DOI: $10.1016 /$ j.jep.2008.02.034.
24. Penso, G., 1980. The role of WHO in the selection and characterisation of medicinal plants. J. Ethnopharmacol., $\quad 2$ : 183-188. http://www.ncbi.nlm.nih.gov/pubmed/7453205.

25. Moure, A., J.M. Cruz, D. Franco, J.M. Dominguez, J. Sineiro, H. Dom'inguez, M.J. 'ũnez and J.C. Paraj'o, 2001. Natural antioxidants from residual sources. Food Chem., 2: 145-171. DOI: 10.1016/S0308-8146(00)00223-5.

26. Galato, D., K. Ckless, M.F. Susin, C. Giacomelli, R.M. Ribeiro do Valle and A. Spinelli, 2001. Antioxidant capacity of phenolic and related compounds: correlation among electrochemical, visible spectroscopy methods and structureantioxidant activity. Redox Report, 6: 243-250. DOI: $10.1179 / 135100001101536391$.

27. Zheng, W. and S.Y. Wang, 2001. Antioxidant activity and phenolic compounds in selected herbs. J. Agri. Food Chem., 49: 5165-5170. http://direct.bl.uk/bld/PlaceOrder.do?UIN=105215 $307 \&$ ETOC $=$ RN $\&$ from $=$ searchengine. 